\title{
Identificación y caracterización de carbohidratos y proteínas en las secreciones del dorso y del pie del molusco Limax flavus
}

\author{
Yanara Astudillo y Carlos A. Soria \\ Laboratorio de Bioquímica, Departamento de Ciencias Biológicas \\ Pontificia Universidad Católica del Ecuador, Quito. casoria@puce.edu.ec
}

Recibido: 09, 05, 2011; aprobado: 19, 09, 2011

\begin{abstract}
RESUMEN.- Adultos del molusco Limax flavus recolectados de los jardines de Quito, Ecuador, fueron adaptados al laboratorio después de lo cual se desarrolló una metodología para obtener muestras de sus secreciones tanto del dorso como del pie; la concentración total de carbohidratos y de proteínas de estas secreciones fueron analizadas con orcinol sulfúrico y ácido bicinconínico BCA respectivamente. En las secreciones del dorso se encontró un promedio de $17875 \mu \mathrm{g}$ de carbohidratos y $19228 \mu \mathrm{g}$ de proteína por cada muestra de secreción liofilizada, en contraste con $1297 \mu \mathrm{g}$ de carbohidratos y $3187 \mu \mathrm{g}$ de proteínas por muestra liofilizada del pie, es decir 14 veces más carbohidratos y 6 veces más proteínas presentes en promedio en las secreciones del dorso comparadas con las encontradas en las secreciones del pie. La caracterización de las proteínas se hizo con electroforesis en gel de poliacrilamida con sodio dodecyl sulfato SDS-Page utilizando muestras procesadas con cloroformo. Se identificaron bandas proteicas de diferentes pesos moleculares en las secreciones del dorso y del pie en un rango que va desde 304 a $6 \mathrm{kD}$. Se reporta que las secreciones del dorso de L. flavus contienen carbohidratos y proteínas más concentrados, pegajosos y con más número de bandas, comparado con las encontradas en las muestras del pie.
\end{abstract}

PALABRAS CLAVES: Limax flavus, carbohidratos, proteínas, secreción

ABSTRACT.- Mollusks of the genus Limax flavus were collected from gardens of Quito, Ecuador, in order to study their external secretions. The adults were adapted to laboratory conditions and a methodology was developed to collect secretions from slugs' backs and feet. The total amounts of carbohydrates and proteins were analyzed with orcinol sulfuric and bicinchoninic acid BCA. An average of 17875 $\mu \mathrm{g}$ of carbohydrates and $19228 \mu \mathrm{g}$ of protein was found for the mucus (liofilized) 
secreted from the dorso. This value is then compared to an average of $1297 \mu \mathrm{g}$ of carbohydrates and $3187 \mu \mathrm{g}$ of protein per liofilized mucus collected from the foot section. The average values obtain from dorsal sections represent 14 times more carbohydrates and 6 times more protein in the dorsal secretion as compared to the average values collected from the foot. Protein characterization was done with sodium dodecyl sulfate SDS-Page polyacrilamide gel electrophoresis, using samples treated with chloroform. Protein bands of different molecular weights in the rank of 304 to $6 \mathrm{kD}$, were present in sticky dorsal secretions, other bands were found in the foot fluids. This research reports important differences in the composition and amount of carbohydrates and proteins between the back and foot secretions of $L$. flavus.

KEYWORDS: Limax flavus, carbohydrates, proteins, secretion

\section{INTRODUCCIÓN}

Los moluscos pulmonados terrestres conocidos como babosas por la presencia de sus secreciones que delatan el lugar por donde se han desplazado, son invertebrados desnudos, de cuerpo húmedo, blando, pegajoso, no segmentado (1) que varían en longitud, masa y color según la familia y la especie. El contorno de una babosa típica es alargado, terminado en punta, con la masa visceral dentro de la cavidad de su cuerpo (2).

Limax flavus (Linnaeus, 1758) está distribuida en toda Europa (3) y ha sido introducida hace años en Japón, en América del Norte y del Sur, en África del sur y en Australia. Es común encontrarlas en jardines, calles o alcantarillas, campos o en otros lugares húmedos y templados. En Ecuador está distribuida en toda la Sierra (4) y se la considera una plaga de vegetales tanto en zonas urbanas como en el campo.
El mucus secretado por estas babosas ha despertado variado interés entre fabricantes de sondas robóticas o en los estudios de adhesivos biodegradables (5) o en su habilidad para antagonizar con neurotoxinas (6). El mucus está constituido por al menos agua, electrolitos y glicoproteínas (7) y su función en estos gastrópodos es la de proteger, lubricar y asistirles en su motilidad.

La secreción de la suela pedía es casi incolora (3) e interviene en la fijación del molusco al sustrato, lo que permite su movilización, proceso conocido como locomoción adhesiva. Además este rastro fluido que va dejando mientras se mueve lentamente, contiene información direccional que es usada para identificación, acoplamiento y depredación (5). Tanto las babosas como sus parientes los caracoles, usan esta delgada barrera de mucus como un mecanismo de protección contra procesos de desecamiento (8). 
Las secreciones del dorso pueden ser ligeramente anaranjadas, amarillas o un tanto incoloras (3). Su producción que generalmente ocurre cuando el molusco se siente amenazado, puede ser considerada como un mecanismo de defensa; la secreción se produce como un fluido bastante líquido, luego se vuelve gelatinoso y pegajoso en pocos segundos $(9,10)$.

No se conoce de estudios hechos en el país en cuanto a la caracterización macromolecular de las secreciones de dorso y de pie de L. flavus locales. El objetivo de nuestro trabajo fue por lo tanto, iniciar estudios moleculares con la identificación y caracterización de carbohidratos y proteínas expresados en estos fluidos considerados como argamasas de bioseñales con algunas funciones aún desconocidas.

\section{MATERIALES Y MÉTODOS}

Recolección e identificación de individuos.- Los individuos fueron recolectados en el norte y sur del Distrito Metropolitano de Quito y del Valle de Los Chillos, Provincia de Pichincha. Se usaron contenedores plásticos para el transporte de adultos al laboratorio donde fueron trasladados a terrarios abiertos $(30 \times 25 \times 20 \mathrm{~cm})$ con una base de tierra de $4 \mathrm{~cm}$ de espesor la cual se mantuvo húmeda al añadirle semanalmente por aspersión $20 \mathrm{~cm}^{3}$ de agua destilada estéril. Se incluyó, dos veces por semana, hojas de lechuga fresca (Lactuca sativa) que les sirvieron de alimento (11). Luego de semanas de ambientación y sobrevivencia, se intentaron varios métodos de extracción y recolección del mucus tanto del pie como del dorso de cada individuo.

Extracción de muestras.- Antes de proceder con la recolección de las secreciones, los animales fueron transferidos a cajas de Petri limpias y estériles, luego fueron lavados con agua destilada y se procedió a remover contaminantes como restos de tierra, comida y heces (5). Seguidamente se les trasladó nuevamente a otras cajas de Petri, igualmente limpias y estériles, en las que caminaban libremente. El mucus del pie que quedaba en la caja (aproximadamente $5 \mathrm{ml}$ por individuo), se recogía con la ayuda de una espátula y se guardaba en tubos Eppendorf de 1,5 ml. El mucus dorsal en cambio, fue recolectado frotando suavemente el dorso de las babosas con una espátula y el fluido que resultaba (aproximadamente $2,5 \mathrm{ml}$ por individuo) se lo recogió igualmente en tubos Eppendorf de acuerdo a la técnica de Pawlicki et al, 2004 (10). Esta opción de recolección de muestras se repitió 2 veces a la semana durante varias semanas.

Los tubos rotulados con las muestras recolectadas fueron envueltos en papel aluminio para protegerlos de la luz, luego fueron guardados y conservados a $-20^{\circ} \mathrm{C}(7,12)$ hasta su uso. 
Concentración de muestras.- Las muestras fueron concentradas por sublimación mediante liofilización. Previo a la liofilización, tanto las muestras del pie como las del dorso almacenadas a $-20^{\circ} \mathrm{C}$ fueron descongeladas, luego trasvasadas a tubos Falcon de $15 \mathrm{ml}$ de capacidad (previamente pesados y rotulados) en volúmenes de 2.5 o $5 \mathrm{ml}$ por tubo. Las muestras en los tubos fueron subsecuentemente congeladas a $-80^{\circ} \mathrm{c}$ durante al menos $15 \mathrm{~h}$. Al día siguiente se procedió con la liofilización durante 8 $\mathrm{h}$ en un equipo Freeze Dryer 5SL. Una vez terminado este proceso, se pesaron los tubos en una balanza analítica para calcular rendimientos y se guardaron los liofilizados a $4^{\circ} \mathrm{C}$ en los mismos tubos en los que se realizó el proceso.

Espectrofotometría de muestras.- Para medir la concentración de carbohidratos en la secreción producida por el dorso o por el pie, se usó la prueba de orcinol-sulfúrico $(13,14)$, modificando el protocolo de Brückner, 1954 (15).

Glucosa (Difco) fue utilizada como muestra estándar en diferentes concentraciones: 0, 125, 250, 500, 750, 1000, 1500 y $2000 \mu \mathrm{g}$ por $\mathrm{ml}$ de reactivo. Un total de $38 \mathrm{mg}$ de muestra liofilizada de mucus de pie obtenidos de seis muestras y $38 \mathrm{mg}$ de mucus liofilizado de dorso obtenidos de una sola muestra, fueron disueltos en $200 \mu \mathrm{l}$ de sodio dodecyl sulfato (SDS) al $1 \%$ por cada miligramo de mucus seco (13) en un volumen total de $7.6 \mathrm{ml}$. De este volumen, (conteniendo $5 \mathrm{mg}$ de liofilizado por $\mathrm{ml}$ ) se tomó $0.5 \mathrm{ml}$ de muestra y se añadió $0.5 \mathrm{ml} \mathrm{de}$ orcinol al 4\% recientemente preparado, se calentó rápidamente hasta ebullición, luego se enfrió en hielo picado y se añadió lentamente gota a gota $1 \mathrm{ml}$ de ácido sulfúrico 98 \% (May \& Baker) para obtener un volumen de $2 \mathrm{ml}$. Se tomó $1 \mathrm{ml}$ de este último compuesto (conteniendo $1250 \mu \mathrm{g}$ de liofilizado por $\mathrm{ml}$ ) y $1 \mathrm{ml}$ de cada dilución de los estándares para determinar la concentración de azúcares usando un espectrofotómetro (Thermo Scientific) a una longitud de onda de $540 \mathrm{~nm}$.

La determinación del contenido proteico de los dos tipos de secreciones se realizó con el ensayo conocido como ácido bicinconínico (BCA) de Pierce Chemical Co. Thermo Scientific (5, 9, $10,13,14,16)$, siguiendo el protocolo similar al procedimiento en tubos que se utilizó para los carbohidratos. En este caso, los tubos conteniendo albúmina bovina (Pierce) en concentraciones de $0,25,125,250,500,750,1000,1500 \mathrm{y}$ $2000 \mu \mathrm{g}$ por $\mathrm{ml}$ de reactivo, fueron utilizados como proteínas estándar.

Una vez disueltos en 1\% SDS los 38 mg de liofilizados tanto del pie como del dorso, se tomó $0.5 \mathrm{ml}$ de cada muestra y $0.5 \mathrm{ml}$ de reactivo SDS-Page hasta completar $1 \mathrm{ml}$ de cada muestra (conteniendo $2500 \mu \mathrm{g}$ de liofilizado por $\mathrm{ml}$ ) y se procedió a calentarlos en baño maría por 30 minutos a $37^{\circ} \mathrm{C}$, luego se midieron 
las absorbancias espectrofotométricas a $562 \mathrm{~nm}$ conjuntamente con los estándares en celdas conteniendo $1 \mathrm{ml}$.

Preparación de muestras y caracterización de proteínas.- Las muestras de dorso y de pie tanto crudas $(50 \mathrm{mg}$ ) como liofilizadas ( $2 \mathrm{mg}$ ) fueron homogenizadas en $100 \mu \mathrm{l}$ de TRIS- $\mathrm{HCl} 1 \mathrm{M}, \mathrm{pH}$ 7.4 y sometidas a diferentes tratamientos previo a la electroforesis, modificando los protocolos usados por Smith y Morin, 2002 (13) y Rosenberg, 2005 (17).

Se usaron 7 procedimientos diferentes de desnaturalización proteica pero en el presente artículo solo nos referimos a la desnaturalización con un volumen de cloroformo $99.9 \%$ (tricloruro de metilo, Mallinckrodt) y uno de muestra; esta mezcla fue incubada a temperatura ambiente durante $20 \mathrm{~min}$, luego fue centrifugada a $10000 \mathrm{rpm}$ en una centrífuga Spectrofuge 24D durante $5 \mathrm{~min}$. Se removió el sobrenadante y el pellet fue disuelto en 3 volúmenes de Tris-HCL para proceder luego a calentarlo o no durante 1 min en agua en ebullición como tratamiento previo al análisis electroforético del precipitado.

Electroforesis en geles de poliacrilamida.- La caracterización proteica se llevó a cabo en geles de poliacrilamida con sodio dodecyl sulfato SDS-Page, modificando procedimientos anteriores $(18,19)$. Las proteínas del dorso y del pie desnaturalizadas con cloroformo, fueron separadas en geles de poliacrilamida al $8 \%$ con electroforesis unidireccional.
Los geles tenían un espesor de $8 \mathrm{~mm}$ con 10 pocillos para las muestras. La capacidad de los pocillos fue de $35 \mu 1$. Se cargó en cada pocillo $25 \mu 1$ de muestra y $5 \mu 1$ de tampón de carga que consistió de $20 \%$ glicerol, $10 \%$ SDS, $10 \%$ b-mercaptoetanol, $1 \% 0.003 \mathrm{M}$ Azul de Comassie en una cantidad suficiente de $1.12 \mathrm{M}$ Tris para $100 \%$. El marcador molecular SeeBlue ${ }^{\circledR}$ Plus 2 Pre Stained Standard de Invitrogen $(10 \mu \mathrm{l}$ por posillo) permitió visualizar rangos de pesos moleculares en kilo Daltons (kD) de las diferentes bandas obtenidas de 4 muestras de cada secreción y de cada tratamiento. Las bandas reportadas son el resultado de 4 repeticiones.

El gel corrió en tampón 1X de TRIS/ $\mathrm{HCl}, \mathrm{pH} 8.3$, en una cámara de electroforesis Fisher Scientific FB-VE10-1, a 130 $\mathrm{V}$, durante $1: 40 \mathrm{~h}$ a $2 \mathrm{~h}$ aproximadamente o hasta que el buffer de carga se ubique a $0.5 \mathrm{~cm}$ del borde inferior del gel.

Tinción del gel con Azul de Comassie.- Las proteínas separadas en el gel por electroforesis fueron coloreadas con el tinte Azul de Comassie al $0.2 \%$ en $33 \%$ metanol y $67 \%$ ácido acético. Se colocó el gel en una fuente conteniendo el tinte y se le calentó en un horno microondas Panasonic durante $1 \mathrm{~min}$. Para remover la coloración no fijada se agitó el gel durante $20 \mathrm{~min}$, luego se procedió a lavarlo con abundante agua destilada y se le colocó durante $2 \mathrm{~h}$ en $400 \mathrm{ml}$ de una solución de desteñido que consistió de $40 \mathrm{ml}$ de ácido acético, 180 
$\mathrm{ml}$ de metanol y $180 \mathrm{ml}$ de agua destilada, para ser calentado nuevamente en el horno microondas durante un minuto. Seguidamente se agitó el gel manualmente durante $15 \mathrm{~min}$ y se procedió a lavarlo con agua destilada. El gel fue expuesto a la solución de desteñido y a calentamiento las veces que fueran necesarias hasta poder observar las bandas proteicas.

Una vez revelados los geles, se les fotografió con una cámara digital Canon y los resultados fueron analizados con el programa Photocapt.

\section{RESULTADOS}

Espectrofotometría de muestras.Se determinó que la concentración de carbohidratos (Tabla 1) en el mucus del dorso es mayor que en el mucus del pie (Tabla 2). Una muestra de $0.5 \mathrm{ml}$ tomada de los $7.6 \mathrm{ml}$ en los que se disolvió los $38 \mathrm{mg}$ de muestra liofilizada resultante de una colecta de $2.5 \mathrm{ml}$ de secreción dorsal, fue mezclada con 0.5 $\mathrm{ml}$ de orcinol 4\% y $1 \mathrm{ml}$ de ácido sulfúrico para dar un volumen de $2 \mathrm{ml}$. De este volumen se tomó $1 \mathrm{ml}$ conteniendo $1250 \mu \mathrm{g}$ de liofilizado que dieron una absorbancia de 0.34 , promedio de 5 repeticiones a una longitud de onda de $540 \mathrm{~nm}$; lo que equivale a una concentración de $588 \mu \mathrm{g}$ de carbohidratos por $\mathrm{ml}$ de reactivo. Los cálculos señalan una concentración de carbohidratos equivalentes a $17875 \mu \mathrm{g}$ promedio por secreción dorsal liofilizada.
Las muestras de pie dieron una absorbancia promedio de 0.27 equivalente a una concentración de $256 \mu \mathrm{g}$ de carbohidratos por $\mathrm{ml}$ de reactivo o a una concentración de $1297 \mu \mathrm{g}$ de carbohidratos por secreción liofilizada de pie, siendo así que cada secreción promedio obtenida del dorso contiene 14 veces más carbohidratos que una secreción promedio obtenida del pie $(\mathrm{z}=-2.643 ; \mathrm{p}=0.008)$.

Las absorbancias y las concentraciones proteicas de las muestras de mucus dorsal se presentan en la Tabla 3. Las muestras de las secreciones del pie presentaron una absorbancia promedio de 1,58 a $562 \mathrm{~nm}$, equivalente a $1265 \mu \mathrm{g}$ de proteína por $\mathrm{ml}$ de reactivo igual a $19228 \mu \mathrm{g}$ de proteína por muestra de secreción dorsal.

La absorbancia promedio del mucus del pie fue de 1.54 correspondiente a una concentración de $1258 \mu \mathrm{g}$ de proteína por $\mathrm{ml}$ de reactivo igual a $3187 \mu \mathrm{g}$ de proteína por secreción promedio liofilizada (Tabla 4). Es decir que el contenido de proteínas de la secreción promedio producida por el dorso es 6 veces más rica en proteínas que su equivalente producida por el pie ( $\mathrm{z}$ $=-2.309 ; \mathrm{p}=0,021$ ).

Electroforesis en geles de poliacrilamida.- Las secreciones tratadas con cloroformo y luego calentadas o no en agua a ebullición, presentaron bandas proteicas de diferentes pesos moleculares (Tablas 5 y 6, figura 1). Con las secreciones del dorso (Tabla 5) crudas y calentadas se obtuvo 17 bandas con 
pesos moleculares diferentes en el rango de 304 a $8 \mathrm{kD}$, mientras que con la misma secreción sin calentamiento se obtuvieron 13 bandas con pesos moleculares entre 289 y $7 \mathrm{kD}$. Con otras secreciones liofilizadas calentadas se observaron 10 bandas entre 268 y $8 \mathrm{kD}$ mientras que al no calentarse se separaron 12 bandas cuyos pesos fluctuaron entre 268 y $6 \mathrm{kD}$.

Las secreciones del pie (Tabla 6) crudas y calentadas mostraron 8 bandas con pesos entre 250 y $9 \mathrm{kD}$ mientras que las mismas muestras sin calentamiento previo solo dieron 6 bandas entre 265 y $12 \mathrm{kD}$. Otras secreciones liofilizadas y calentadas mostraron 13 bandas de 287 a $9 \mathrm{kD}$; con muestras sin calentamiento previo se obtuvieron 12 bandas, entre 287 y $13 \mathrm{kD}$.

\section{DISCUSIÓN}

Limax flavus fue identificado por la coloración gris verdosa de la piel del dorso, la ausencia total de concha, el color claro de la suela pedia, la secreción color plata transparente del pie y el color crema anaranjado del fluido del dorso, características que se utilizaron para identificar y diferenciarlo fácilmente de otros moluscos como Veronicella o Sarasinula (3) igualmente presentes en nuestro medio (4).

La adaptabilidad de L. flavus a las condiciones del laboratorio, la facilidad para la recolección de secreciones y el cuidado para evitar contaminación entre secreciones, facilitaron la conducción de este estudio. Se pudo demostrar que más del $98 \%$ del volumen de las secreciones estaba constituido de agua sublimable y de una mínima cantidad de producto liofilizado, entre 6 y $38 \mathrm{mg}$ por muestra colectada, sea de pie $(5 \mathrm{ml})$ o de dorso $(2.5 \mathrm{ml})$ respectivamente, lo que demuestra que las secreciones del dorso son como 6 veces más ricas en masa liofilizable que las del pie, aunque está entendido que algo de sólidos se pierden cuando se remueven los cristales de agua. Porcentajes más o menos similares han sido reportados en la composición de otras secreciones como en las de Lehmannia valentiana, igualmente en las secreciones de otros gastrópodos o en la de algunos gusanos $(9,13,14,16)$.

El reactivo orcinol-ácido sulfúrico, permitió estimar reacciones colorimétricas de carbohidratos conteniendo hidrofenoles formados por condensación de furfurales e hidroximetilfurfurales con ácidos minerales fuertes como el ácido sulfúrico, a temperaturas, tiempos, concentraciones y absorbancias estandarizadas (15). Estas reacciones detectaron colorimétricamente y por espectrofotometría (a $540 \mathrm{~nm}$ ) la presencia y la cantidad de carbohidratos tanto en el dorso como en el pie de L. flavus. Se reporta $17875 \mu \mathrm{g}$ de carbohidratos en $38 \mathrm{mg}$ de muestra promedio de $2.5 \mathrm{ml}$ tomada del dorso, a diferencia de las secreciones del pie donde se encontró en promedio 1297 $\mu \mathrm{g}$ de carbohidratos en $6.3 \mathrm{mg}$ de liofilizado en los $5 \mathrm{ml}$ promedio de muestra. 
Las secreciones del dorso son por lo tanto 14 veces más ricas en cantidad de carbohidratos comparadas con las del pie lo que les hace diferentes a las dos secreciones, al menos en concentración y en capacidad adherente de los carbohidratos, esta última propiedad parece depender proporcionalmente de la concentración molecular, entre otros.

La detección y cuantificación de proteínas con BCA-Pierce (Thermo Scientific) en el rango de 20 a $2000 \mu$ g por $\mathrm{ml}$, se basa en la propiedad de las proteínas para reducir $\mathrm{Cu}+2 \mathrm{a} \mathrm{Cu}+1$ en medio alcalino y de la habilidad del ácido bicinconinico para quelar $\mathrm{Cu}+1$ y formar complejos hidrosolubles de color que absorben luz a $562 \mathrm{~nm}$, proporcional a la concentración de las proteínas.

Con esta metodología se encontró $19228 \mu \mathrm{g}$ promedio de proteína por muestra de dorso. Mientras que en el pie solamente se obtuvo $3187 \mu \mathrm{g}$ de proteína por muestra recolectada. Es decir 6 veces más proteína promedio en las secreciones del dorso que en las del pie.

Los datos igual indican que en las secreciones del dorso, tanto los carbohidratos $(17875 \mu \mathrm{g} /$ muestra $)$ como las proteínas $(19228 \mu \mathrm{g} / \mathrm{muestra})$ están presentes en similares proporciones (de un total de $38 \mathrm{mg}$ de liofilizado promedio por muestra), lo cual es poco usual si se tratara de glicoproteínas convencionales, mientras que en las del pie, como si fueran glicoproteínas comunes, hay como 3 veces más proteínas $(3187 \mu \mathrm{g} /$ muestra) que carbohidratos $(1297 \mu \mathrm{g} /$ muestra), de un total de $6.3 \mathrm{mg}$ de liofilizado obtenidos de una colecta promedio. Estos datos también indican que tanto en las secreciones del dorso como en las del pie deben existir otros sólidos liofilizados aparte de los carbohidratos y proteínas estudiados. Los resultados igual explican por qué las secreciones del pie son más fluidas que las del dorso y por qué estas últimas son más viscosas, no solamente por la mayor cantidad de liofilizado encontrado por unidad de volumen, sino también por el alto contenido (poco común) de carbohidratos y proteínas mucilaginosas presentes en dichas secreciones dorsales.

Es interesante el hecho de no haber podido correr electroforesis con las muestras liofilizadas o frescas en vista de que no se solubilizaban adecuadamente en el buffer de carga. La limitación de complejos similares para poder correr en geles electroforéticos también fue reportado en L. valentiana (5), de ahí que se hizo necesario desnaturalizar las secreciones proteicas siguiendo varios procedimientos, la mayoría de ellos no discutidos en este trabajo.

El cloroformo es solvente de mucinas, grasas y aceites hidrofóbicos, debido a su carácter polar, lo que nos hace suponer que fracciona los componentes proteicos de los muco y glico compuestos, permitiendo que aniones detergentes como el SDS sodio dodecylsulfato del grupo de los alquilsulfatos forme 
enlaces por condensación, disminuya la tensión superficial y denature a las fracciones proteicas (20), volviéndolas solubles y fácilmente separables en geles electroforéticos.

Con esta metodología se observó un patrón similar de bandas proteicas tanto en las muestras de mucus dorsal (de 304 a $6 \mathrm{kD}$ ) como en las del pie (de 287 a 9 $\mathrm{kD}$ ), encontrándose bandas similares (de $250 \mathrm{kD}$ para arriba) pero notoriamente con más bandas pequeñas (13 bandas de $15 \mathrm{kD}$ para abajo) en el dorso comparado con el pie (5 bandas). Un patrón similar se reporta en L. valentiana (5) y A. subfucus (10).

Se observa en general, un mayor número de bandas en las secreciones crudas y liofilizadas calentadas comparadas con las que no fueron sometidas a calentamiento y esto se podría esperar porque la adición de calor a estas muestras aumentaría la actividad molecular de los reactivos, por ende la disgregación proteica.

La presencia de un mayor número de bandas proteicas en las secreciones del dorso (52 en total), comparadas con las del pie (39 bandas), podrían explicar, en parte, las diferencias entre las dos secreciones que se notan inclusive al tacto. La del pie es una secreción con pocas proteínas (6 veces menos) y carbohidratos (14 veces menos) comparado con lo encontrado en el dorso. La secreción del pie, pierde agua rápidamente, se vuelve un polvo delicadamente escamoso al tacto y al restregarlo suavemente se se- para en hojuelas entretejidas muy finas, parcialmente solubles y con capacidad surfactante. En cambio la secreción del dorso aparece líquida inicialmente, luego a los pocos segundos se vuelve un gel adhesivo y viscoso.

La capacidad adherente o pegajosa de la secreción dorsal respondería a la presencia de proteínas conjugadas como las glicoproteínas insolubles y entrecruzadas, difíciles de desnaturalizar, conocidas como mucinas $(21,10,9)$; la proteína prostética se esterifica vía enlaces glicosídicos con los grupos amino o carboxílico y una importante fracción de sacáridos o aminosacáridos de la familia de las aldosas y pentosas como parece insinuar otro de nuestros estudios no reportados en el que se encontró que los carbohidratos, a los que hacemos referencia, eran polisacáridos formados más que nada por pentosas. Son estos polisacáridos covalentemente unidos a las proteínas los que influencian en la estructura, funciones de reconocimiento molecular y estabilidad de las glicoproteínas.

Probablemente otros complejos insolubles de proteína-polisacáridos, con una relación 3 de proteína por 1 de carbohidratos (casi típico de una glicoproteína), menos adhesivos al tacto, fueron los que también se encontraron en las secreciones del pie.

Fracciones proteicas pequeñas (de hasta $60 \mathrm{kD}$ ) consideradas importantes en la mecánica de la formación de geles 
adhesivos (9), fueron encontradas tanto en las secreciones del pie (12 bandas totales) como en las del dorso (17 bandas totales), en mayor cantidad en esta última secreción notoriamente más adhesiva que la del pie. No sabemos si todas o algunas de las bandas proteicas encontradas con bajos pesos moleculares son fracciones de otras más grandes o si son componentes naturales de la secreción.

Quizá estas diferencias significativas en las cantidades y cualidades de proteínas y carbohidratos encontrados en nuestros estudios con L. flavus, nos ayuden a entender algunas propiedades adhesivas, protectoras, surfactantes, receptoras o antagónicas de señales $(5,8$, $9,10,22)$ atribuidas a algunas secreciones de molusca.

\section{AGRADECIMIENTOS}

A la Pontificia Universidad Católica del Ecuador por la asignación de fondos de investigación a través del Proyecto: Biomoléculas potencialmente aplicables.

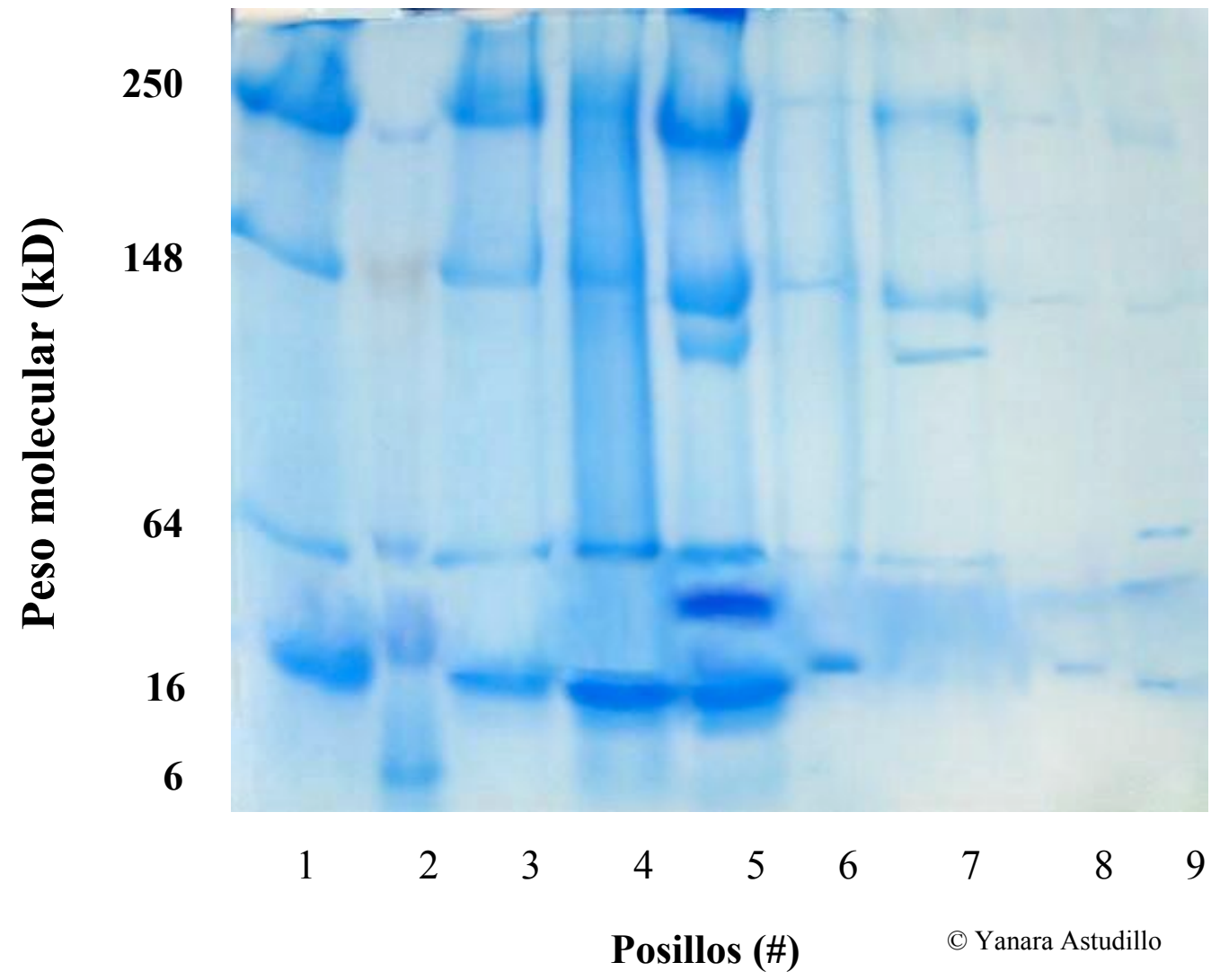

Figura 1. Electroforesis de secreciones crudas y liofilizadas tratadas con cloroformo 1. DLS, 2. Marcador SeeBlue Plus, 3. DLC, 4. DCS, 5. DCC, 6. PLS, 7. PLC, 8. PCS, 9. PCC. 
Tabla 1. Concentración de carbohidratos en muestras de secreciones del dorso de Limax flavus. Los $\mu \mathrm{g} /$ muestra se obtienen multiplicando los $\mu \mathrm{g} / \mathrm{ml}$ reactivo por 2 y por 2 (volumen del reactivo) y por 7.6 (volumen de la muestra analizada). Los $\mu \mathrm{g} / \mathrm{ml}$ reactivo se obtienen de la curva de absorbancia de los estándares.

\begin{tabular}{clcc}
\hline Muestra & $\begin{array}{c}\text { Absorbancia } \\
(\mathbf{5 4 0} \mathbf{~ n m})\end{array}$ & $\boldsymbol{\mu g} / \mathbf{m l}$ reactivo & $\boldsymbol{\mu g} / \mathbf{m u e s t r a}$ \\
\hline 1 & 0.42 & 840 & 25536 \\
2 & 0.35 & 650 & 19760 \\
3 & 0.30 & 400 & 12160 \\
4 & 0.30 & 400 & 12160 \\
5 & 0.35 & 650 & 19760 \\
Promedio & 0.34 & 588 & 17875 \\
\hline
\end{tabular}

Tabla 2. Concentración de carbohidratos en muestras de secreciones del pie de Limax flavus. Los $\mu \mathrm{g} /$ muestra se obtienen multiplicando los $\mu \mathrm{g} / \mathrm{ml}$ reactivo por 2 y por 2 (volumen del reactivo), por 7.6 (volumen de la muestra analizada), dividido para 6 (número de muestras liofilizadas). Los $\mu \mathrm{g} / \mathrm{ml}$ reactivo se obtienen de la curva de absorbancia de los estándares.

\begin{tabular}{cccc}
\hline Muestra & $\begin{array}{c}\text { Absorbancia } \\
(\mathbf{5 4 0} \mathbf{~ n m})\end{array}$ & $\boldsymbol{\mu g} / \mathbf{m l}$ reactivo & $\boldsymbol{\mu g} /$ muestra \\
\hline & 0.30 & 400 & 2027 \\
2 & 0.21 & 100 & 507 \\
3 & 0.28 & 190 & 963 \\
4 & 0.30 & 400 & 2027 \\
5 & 0.28 & 190 & 963 \\
Promedio & 0.27 & 256 & 1297 \\
\hline
\end{tabular}


Tabla 3. Concentración de proteínas en muestras de secreciones del dorso de Limax flavus. Los $\mu \mathrm{g} /$ muestra se obtienen multiplicando los $\mu \mathrm{g} / \mathrm{ml}$ reactivo por 2 (volumen del reactivo) y por 7.6 (volumen de la muestra analizada). Los $\mu \mathrm{g} / \mathrm{ml}$ reactivo se obtienen de la curva de absorbancia de los estándares.

\begin{tabular}{cccc}
\hline Muestra & Absorbancia & $\begin{array}{c}\boldsymbol{\mu g} / \mathbf{m l} \text { reactivo } \\
(\mathbf{5 6 2} \mathbf{~ n m})\end{array}$ & $\boldsymbol{\mu g} /$ muestra \\
\hline 1 & 1.43 & 1060 & 16112 \\
2 & 1.56 & 1250 & 19000 \\
3 & 1.67 & 1390 & 21128 \\
4 & 1.64 & 1360 & 20672 \\
Promedio & 1.58 & 1265 & 19228 \\
\hline
\end{tabular}

Tabla 4. Concentración de proteínas en muestras de secreciones del pie de Limax flavus. Los $\mu \mathrm{g} /$ muestra se obtienen multiplicando los $\mu \mathrm{g} / \mathrm{ml}$ reactivo por 2 (volumen del reactivo), por 7.6 (volumen de la muestra analizada), dividido para 6 (número de muestras liofilizadas). Los $\mu \mathrm{g} / \mathrm{ml}$ reactivo se obtienen de la curva de absorbancia de los estándares.

\begin{tabular}{cccc}
\hline Muestra & $\begin{array}{c}\text { Absorbancia } \\
(\mathbf{5 6 2} \mathbf{~ n m})\end{array}$ & $\boldsymbol{\mu g} / \mathbf{m l}$ reactivo & $\boldsymbol{\mu g} / \mathbf{m u e s t r a}$ \\
\hline 1 & 1.68 & 1400 & 3547 \\
2 & 1.60 & 1300 & 3293 \\
3 & 1.65 & 1370 & 3471 \\
4 & 1.24 & 960 & 2432 \\
Promedio & 1.54 & 1258 & 3187 \\
\hline
\end{tabular}


Tabla 5. Identificación proteica de las secreciones del dorso en geles de SDS-Page. Los números corresponden al peso molecular de la banda en kilo Daltons (kD).

\begin{tabular}{lccc}
\hline DCC & DCS & DLC & DLS \\
\hline 304 & 289 & 268 & 268 \\
285 & 276 & 267 & 157 \\
257 & 271 & 148 & 148 \\
254 & 267 & 143 & 135 \\
235 & 228 & 137 & 70 \\
145 & 168 & 135 & 69 \\
142 & 165 & 63 & 40 \\
141 & 148 & 57 & 38 \\
135 & 146 & 9 & 12 \\
131 & 64 & 8 & 11 \\
128 & 10 & & 6 \\
62 & 8 & & \\
23 & 7 & & \\
14 & & & \\
13 & & & \\
10 & & & \\
8 & & & \\
\hline
\end{tabular}

DCC: Dorso crudo calentado, DCS: Dorso crudo sin calentar, DLC: Dorso liofilizado calentado, DLS: Dorso liofilizado sin calentar 
Tabla 6. Identificación proteica de las secreciones del pie en geles de SDS-Page. Los números corresponden al peso molecular de la banda en kilo Daltons $(\mathrm{kD})$.

\begin{tabular}{llll}
\hline PCC & PCS & PLC & PLS \\
\hline 250 & 265 & 287 & 287 \\
246 & 262 & 267 & 284 \\
141 & 141 & 259 & 278 \\
140 & 140 & 250 & 252 \\
71 & 15 & 242 & 250 \\
46 & 12 & 145 & 147 \\
44 & 144 & 146 & \\
9 & 142 & 144 & \\
& 141 & 60 & \\
& 130 & 59 & \\
& 57 & 16 & \\
& 54 & 13 & \\
& 9 & & \\
& & & \\
\hline
\end{tabular}

PCC: Pie crudo calentado, PCS: Pie crudo sin calentar, PLC: Pie liofilizado calentado, PLS: Pie liofilizado sin calentar

\section{REFERENCIAS}

\section{BIBLIOGRÁFICAS}

1. GONZALES, L.E. 2005. Guía para el control de babosas (Mollusca: Gastropoda) en el Perú. Servicio Nacional de Sanidad Agraria, Ministerio de Agricultura, Perú.

2. SOUTH, A. 1992. Terrestrial slugs: Biology, Ecology and Control. Chapman \& Hall. London. 428 pp.

3. CASTILLEJO, J. 1998. Guía de las babosas Ibéricas. Real Academia
Gallega de Ciencias. Graficolor MINERVA. S.L. Santiago de Compostela, España. 154 pp.

4. CORREOSO, M. 2008. Los moluscos terrestres y fluviales de Ecuador continental. La biodiversidad desconocida. SIMBIOE, Quito, Ecuador p. 100-101.

. LI, D. \& GRAHAM, LL. 2007. Epidermal secretions of terrestrial flatworm and Slug: Lehmania valentiana mucus contains matrilin- 
like proteins. Comparative Biochemistry and Physiology, Part B 148: 231-244.

6. BAKRY, N.; KAMATA, Y. \& SIMPSON, L.L. 1991. Lectins from Triticum vulgaris and Limax flavus are universal antagonists of botulinum neurotoxin and tetanus toxin. The Journal of Pharmacology and Experimental Therapeutics 258 (3): 830-836.

7. DEYRUP-OLSEN, I.; LUCHTEL, D. L. \& MARTINA. W. 1983. Components of mucus of terrestrial slugs (Gastropoda). American journal of Regulatory, Integrative and Comparative Physiology 245: 448-452.

8. DENNY, M.W. 1989. Invertebrate mucous secretions: Fuctional alternatives to vertebrate paradigms. Symposia of the Society for Experimental Biology 43: 337-336.

9. SMITH, A. 2006. The Biochemistry and mechanics of gastropod adhesive gels in biological adhesives. Springer-Verlag, Berlin Heidelberg. p. 167-182.

10. PAWLICKI, J.M.; PEASE, L.B.; PIERCE, C.M.; STARTZ, T.Z.; ZHANG, Y. \& SMITH, A.M.. 2004. The effect of molluscan glue proteins on gel mechanics. Journal of Experimental Biology 207: 11271135.

11. CLEMENTE, N.L.; FABERI, A.J.; LÓPEZ, A.N; MANNETI, P.L. \& ÁLVAREZ H.A. 2007. Biología de
Deroceras reticulatum y D. leave, moluscos de cultivos en siembra directa. RIA, INTA- Argentina 36 (2): 129-142.

12. LIRA, A. 2008. "Determinación de alantoína en secreción del caracol Chileno (Helix aspersa Müller). Variaciones en su concentración según tipo de alimentación y época de obtención en el año. Disertación previa a la obtención del Título de Licenciado en Química Farmacéutica. Universidad Austral de Chile, Facultad de Ciencias, Escuela de Química y Farmacia. Chile.

13. SMITH, A. \& MORIN M, 2002. Biochemical differences between trail mucus and adhesive mucus from Marsh Periwinkle snails. Biological Bullet. 203: 338-346.

14. SMITH, A.; QUICK, T. \& PETER, R. 1999. Differences in the composition of adhesive and non-adhesive mucus from the Limpet Lottia limatula. Biological Bullet. 196: 33-44.

15. BRUCKNER, J. 1954. Estimation of monosaccharides by the OrcinolSulphuric acid reaction. Biochemical Journal 60 (2): 200-205.

16. MCGEE, C.; WISDOM, G.; FAIRWEATHER, I.; BLACKSHAW, R.; MCILROY, J. \& WALHHER, C. 1998. Characterization of the protein present in the mucus of the flatworm Artioposthia triangulata (Dendy). Comparative Biochemistry Physiology 119 (2): 293-298. 
17. ROSENBERG, I. 2005. Protein analysis and purification: Benchtop techniques. Editorial Springer. 520 pp.

18. PÉREZ, O. 2002. Expresión de las proteínas asociadas a la lámina nuclear "(LAP2) y Lamin B en anfibios ecuatorianos (Anura, Urodela y Gymnophiona). Disertación previa a la obtención del Título de Licenciado en Ciencias Biológicas. Pontificia Universidad Católica del Ecuador. Quito- Ecuador.

19. DEL PINO, E.; SAENZ, F.; PÉREZ, O.; BROWN, F.; AVILA, M.; BARRAGÁN, V.; HADDAD, N.; PAULIN M. \& KROHNE, G. 2002. Lamina-asociated polypeptide 2 (LAP2) expression in fish and amphibians. Int. J. Dev. Biol. 46: $227-$ 234.
20. BERG, J.; TYMOCZKO, J. \& STRYER, L. 2007. Biochemistry. W.H. Freeman and Company, Edición 6, Ney York, USA. 1126 pp.

21. VERDUGO, P.; DEYRUP-OLSEN, I.; AITKEN, M.; VILLALON, M. \& JOHN SON, D. 1987. Molecular mechanism of mucin secretions: The role of intragranular charge shielding. Journal of Dental Research 66(2): 506-508.

22. EDWOLDT, R.; CLASEN, C.; HOSOI, A.; MCKINLEY. 2006. Rheological fingerprinting of gastropod pedal mucus and synthetic complex fluid for biomimicking adhesive locomotion. The Royal Society of Chemistry 3: 634- 643. 